\title{
ANALYSIS AND OPTIMIZATION OF MECHANICAL UTILITY
} SYSTEM

\author{
Deeptej G. Kolambkar ${ }^{1}$, Pooja K. Nandu ${ }^{2}$, Kiran K. Sinkar ${ }^{3}$, Simran A. Sohal ${ }^{4}$ \\ ${ }^{1,2,3,4}$ B.E Student, Department of Mechanical Engineering, Datta Meghe College of Engineering, Maharashtra, India
}

\begin{abstract}
The present paperhas discussed the analyzing and optimizing methodology of mechanical utility systems.A study was carried out at Melog Speciality ChemicalsLtd with the aim of optimising the company's utility system efficiency. Energy conservation is a worldwide, concern and an important consideration for any industry. In a chemical plant, amajor portion of the supplied energy is consumed in the production of compressed air. This compressed air is used for various applications. Hence in order to increase the efficiency of the plant the input energy supplied has to be decreased by making use of the most effective methods of compression which indirectly results in asaving of power.The paper revolves around the main objective of reducing the compression cost of air. This aim has been theoretically achieved by replacing the existing reciprocating compressor with a screw compressor. Cost saving due to the use of screw compressor is achieved because it requires low motor power to operate as compared to its reciprocating counterpart. Also, thereciprocating compressor needs frequent maintenance of various components like $v$ - belt, piston rings, piston, etc. whereas screw compressor does not require frequent maintenance which decreases the compression system's maintenance downtime. As there is no intercooler required in screw compressor the need to pump the cooling water at an intermediate stage of compression is eliminated, which is otherwise necessary for optimum operation reciprocating compressor.
\end{abstract}

Keywords: Utility System, Economic Cost, Energy Conservation, Reciprocating Compressor, Screw Compressor.

\section{INTRODUCTION}

The heart of any chemical plant is its mechanical utility system. Utility system consists of energy utilizing equipment which converts electrical energy and heat energy into required work output [1]. A utility system is an important part of many chemicals and mechanical industries. The last 10 years has seen major efforts for economic and thermodynamic optimization of utility systems. The environmental project arrangement of utility systems integrating pollutant secretion abatement technologies has had a major influence on financial cost, pollutant discharge, and energy ingestion of the chemical industry [2]. Utility system mainly consists of air compressor, boiler, chilling plant, nitrogen separator, etc. In Melog Speciality chemicals, primary inspection and study of the utility system revealed problems associated with the air compression system. Henceforth the project consists of a technical and monetary analysis of the existing compression systems and its comparison with the modern screw compression technology.

\subsection{Compression System in Utility}

In most process industries, prime importance is given to compressed air, primarily obtained from compressors. In Melog Speciality Chemicals Pvt. Ltd. there is a requirement of compressed air for nitrogen generation and operation of various pneumatic valves in a chemical plant. For efficient generation nitrogen adsorption process is used. The process requires air with a mass flow rate of $100 \mathrm{Nm}^{3} / \mathrm{hr}$. This flow rate of air is obtained by compressing ambient air to a pressure of $7.7 \mathrm{Kg} / \mathrm{cm}^{2}$ in a 2 stage reciprocating air compressor. The compressed air is then passed through a Carbon Molecular Sieve (CMS). Oxygen and other gases are adsorbed on the CMS surface \& only nitrogen is passed to the storage cylinder. Pure nitrogen in the storage is then delivered to the chemical plant to carry out processing of dyes and resins[3].

\section{POWER CONSUMPTION \& SAVINGS}

Any general compressed air system normally requires up to $8 \mathrm{hp}$ of electrical power to operate a unit hp air compressor motor. Thus, theair compressor is usually considered luxurious to run. The cost of electricity required to operate a typical compressor for 2 years usually exceeds the initial capital investment for the compressed air system. The maintenance costs contribute to over $10 \%$ of the initial investment made by the company. Due to all these reasons, the operating overall efficiency of the compressed air systems generally drops below $15 \%$. The compressed air systems thus being an inefficient source of energy needs optimization in its power consumption which might result in an increase in the system's efficiency. The following procedure was adopted by us to calculate the saving in power consumption if a 2 stage reciprocating compression system is replaced by a single stage screw compression system.

\subsection{Saving In Compression Power}

Existing reciprocating compressor in the utility system is of $45 \mathrm{KW}$ (maximum rating). The motor works on variable 
load over the period of one day. Full load and No load power consumption are calculated as follows:

$\mathrm{P}=\frac{\sqrt{3} \times \mathrm{v} \times \mathrm{I} \times \mathrm{PF}}{1000}(\mathrm{KW})$

Given operational voltage as 380 volts with a power factor of 0.9.Full load current as 70A. No load current as 35A.Electricity Tariff was taken as Rs $\left(7.7 / \mathrm{kW}^{*} \mathrm{hr}\right.$.). Therefore,

$\mathrm{P}($ full load $)=\frac{\sqrt{3} \times 380 \times 70 \times 0.9}{1000}=41.465 \mathrm{KW}$

$\mathrm{P}($ no load $)=\frac{\sqrt{3} \times 380 \times 35 \times 0.9}{1000}=20.732 \mathrm{KW}$

The equivalent screw compressor for same parameters requires a $30 \mathrm{KW}$ motor. The power requirement of the screw compressor were found out by law of proportionality with the reciprocating compressor as follows:

$\mathrm{P}($ full load $)=\frac{41}{45} \times 30=27.33 \mathrm{KW}$

$\mathrm{P}($ no load $)=\frac{20}{45} \times 3=13.33 \mathrm{KW}$

In order to calculate what time the compressor is running at full load and no load condition, a general log book reading for the month of September 2015 was considered. The readings are taken by hour-meter instrument were as follows:

Table -1: Average Hour Meter Reading for Compressor

\begin{tabular}{|l|l|l|}
\hline Date & $\begin{array}{l}\text { Full Load } \\
\text { (Hrs.) }\end{array}$ & No Load (Hrs.) \\
\hline $01 / 09 / 2015$ & 1016494 & 601052 \\
\hline $30 / 09 / 2015$ & 1058632 & 621395 \\
\hline $\begin{array}{l}\text { Difference: } \\
\text { (30 days) }\end{array}$ & 42138 & 20343 \\
\hline Average:(For1 day) & $\begin{array}{l}\frac{42138}{30} \\
=1404.6 \\
\approx 14 \mathrm{Hrs}\end{array}$ & $\begin{array}{l}\frac{20343}{30} \\
=678.1 \\
\approx 7 \text { Hrs }\end{array}$ \\
\hline
\end{tabular}

Cost of electricity consumed at full load for a day with reciprocating compressor

$=$ Full load rating $\times$ Number of Hrs $\times$ Tariff

$=41 \times 14 \times 7.7$

= Rs. 4419.8

Cost of electricity consumed at no load for a day with reciprocating compressor

$=$ No load rating $\times$ Number of Hrs. $\times$ Tariff

$=21 \times 7 \times 7.7$

= Rs. 1131.9

The Cost of electricity consumed for an equivalent screw compressor with same operating parameters, calculated as: Cost of electricity at full load for a day

$=$ Full load rating $\times$ Number of Hrs $\times$ Tariff

$=27 \times 14 \times 7.7$

= Rs. 2910.6

Cost of electricity at no load for a day

$=$ No load rating $\times$ Number of Hrs $\times$ Tariff

$=13 \times 7 \times 7.7$

$=$ Rs. 700.7

The following graph shows a comparison between electricity cost of Reciprocating and Screw compressor for a day at full load and no load conditions. The graph gives a very clear explanation of saving in operating cost if the reciprocating compressor is replaced by screw compressor.

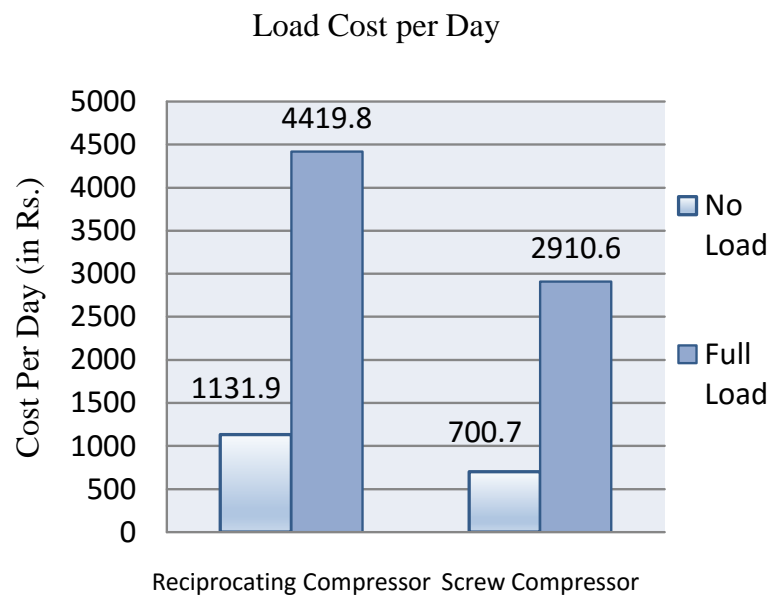

Chart -1: Cost of Electricity Required for Compressor / Day

\subsection{Saving In Electric Consumption}

At full load

$=41-27=14 \mathrm{~kW}$

At no load

$=21-13=8 \mathrm{~kW}$

Saving in cost by screw compressor for one day of operation

At full load

At no load

Total saving

Cost saving for a month

Cost saving for a year

\subsection{Saving In Pumping Cost}

Screw compressor does not require cooling water as it is a single stage compressor. The hot compressed air and oil mixture is separated in an oil separator element from where hot oil is cooled in the radiator. Hence, it results in saving in pumping cost which is necessary for reciprocating compressor [5].

In utility system, the industry requires total $17.5 \mathrm{hp}$ (pump one: $10 \mathrm{hp}$ and pump two: $7.5 \mathrm{hp}$ ) motor for pumping the cooling water for six equipment. Therefore, average hp required for reciprocating compressor of nitrogen separator, 
Power $=17.5 / 6$

$=2.916 \mathrm{hp}$

$=2.175 \mathrm{KW}$.

$(1 \mathrm{hp}=746$

W)

Actual power consumed by motor at full load,

$\begin{aligned} \mathrm{P}_{\mathrm{act}} & =\text { Power factor } \times \mathrm{P} \\ & =0.8 \times 2.175\end{aligned}$

$=1.74 \mathrm{~kW}$.

Electricity Tariff for industry

Total power required for a day

$=$ Rs. $7.7 / \mathrm{kW} * \mathrm{hr}$.

$=1.74 \times 24$

$=41.76 \mathrm{~kW} * \mathrm{hr}$.

Cost saving in a day

$=$ Rs. $(7.7 \times 41.76)$

$=$ Rs. 321.552

$=$ Rs. 9,646.56

Cost saving for a month

$=$ Rs $1,15,758.72$

Annual gross savings possible using screw compressor

$=$ saving in pumping cost + saving in compression cost

$=1,15,758.72+6,98,544$

$=$ Rs. $8,14,302.72$

\section{EFFICIENCY OPTIMISATION}

Compressed air systems generate, store and distribute energy in the form of compressed air for use throughout a plant. In a compressed air system, a single set of compressors can supply power to machines all over the plant, thus eliminating the need for numerous and dispersed electric motors. This advantage must be balanced against the relatively poor energy efficiency of compressed air systems, which can be as low as $20 \%$ when leaks and part-load control losses are taken into account. Thus, increasing the efficiency of compressed air systems can result in significant energy savings [6].

Specifications of nitrogen separator's2 stage reciprocating air compressor previously installed in the utility system were as follows:

\begin{tabular}{|c|c|c|}
\hline 1. & $\begin{array}{l}\text { L.P. Cylinder } \\
\text { HP Cylinder }\end{array}$ & $\begin{array}{l}=255 \mathrm{~mm} \\
=160 \mathrm{~mm}\end{array}$ \\
\hline 2. & Stroke & $=120 \mathrm{~mm}$ \\
\hline 3. & Compressor speed & $=1480 \mathrm{rpm}$ \\
\hline 4. & Free Air Delivery & $=6.95 \mathrm{~m}^{3} / \mathrm{min}$ \\
\hline 5. & Suction pressure & $=1.033 \mathrm{~kg} / \mathrm{cm}^{2}$ \\
\hline 6. & Working pressure & $=7.70 \mathrm{~kg} / \mathrm{cm}^{2}$ \\
\hline 7. & Lubrication oil pressure & $=2$ to $4 \mathrm{~kg} / \mathrm{cm}^{2}$ \\
\hline 8. & Total cooling water & $=40 \mathrm{lpm}$ \\
\hline 9. & Total wt. of compressor & $=1750 \mathrm{~kg}$ \\
\hline \multirow[t]{3}{*}{10.} & Dimensions: & $=3180 \mathrm{~mm}$ \\
\hline & $\mathrm{W}$ & $=1750 \mathrm{~mm}$ \\
\hline & $\mathrm{H}$ & $=1570 \mathrm{~mm}$ \\
\hline
\end{tabular}

\section{Electric motor $\quad=45 \mathrm{~kW}, 1475 \mathrm{rpm}[7]$}

The overall efficiency of the existing reciprocating compressor was calculated in preliminary analysis as follows:

$\eta_{\text {Volumetric }}=\left\{1-\mathrm{c} \times\left[\left(\frac{\mathrm{P}_{2}}{\mathrm{P}_{1}}\right)^{\frac{1}{\gamma}}-1\right]\right\} \times \frac{\mathrm{P}_{1} \mathrm{~T}_{0}}{\mathrm{P}_{0} \mathrm{~T}_{1}} \times 100$
$\eta_{V}=\left\{1-0.05 \times\left[\left(\frac{2.82}{1.0326}\right)^{\frac{1}{1.4}}-1\right]\right\} \times \frac{103.26 \times 273}{1 \times 300}$
$\eta_{V}=95.06 \%$

Swept volume $\left(\dot{\mathrm{V}}_{\mathrm{s}}\right)$ :

$\dot{\mathrm{V}}_{\mathrm{s}}=\frac{\pi}{4} \times \mathrm{D}^{2} \times \mathrm{L} \times \frac{\mathrm{N}}{60} \dot{\mathrm{V}}_{\mathrm{s}}=\frac{\pi}{4} \times 0.255^{2} \times 0.12 \times \frac{725}{60}$

$\dot{\mathrm{V}}_{\mathrm{s}}=74.05 \times 10^{-3} \mathrm{~m}^{3} / \mathrm{s}$

Hence, the free air delivery to the compressor was

$\left(\dot{\mathrm{V}}_{1}\right)=\eta_{\mathrm{V}} \times \dot{\mathrm{V}}_{\mathrm{s}}\left(\dot{\mathrm{V}}_{1}\right)=0.9506 \times 74.0522 \times 10^{-3}$

$\left(\dot{\mathrm{V}}_{1}\right)=70.39 \times 10^{-3} \mathrm{~m}^{3} / \mathrm{s}$

Free air delivery to Low-pressure cylinder $\quad=257.4 \mathrm{cfm}$ $=6.95 \mathrm{~m}^{3} / \mathrm{min}$ $=0.1158 \mathrm{~m}^{3} / \mathrm{s}$

Ideal work done on air or Ideal power input required to compressor was calculated using the standard imperial formula as follows:

$\dot{\mathrm{W}}=2\left[\frac{\gamma}{\gamma-1} \mathrm{P}_{1} \dot{\mathrm{V}}_{1}\left[\left(\frac{\mathrm{P}_{2}}{\mathrm{P}_{1}}\right)^{\frac{\gamma-1}{\gamma}}-1\right]\right]$
$\dot{\mathrm{W}}=2\left[\frac{1.4}{1.4-1} \times 103.26 \times 0.1158\left[\left(\frac{2.82}{1.0326}\right)^{\frac{1.4-1}{1.4}}-1\right]\right]$
$\dot{\mathrm{W}}=27.829 \mathrm{~kW}$

From the calculated data the overall efficiency of the 2 stage reciprocating air compressor was computed as follows:

$$
\begin{aligned}
\eta_{\text {overall }} & =\frac{\text { Ideal Work }}{\text { Motor Power }} \times 100 \\
\eta_{\text {overall }} & =\frac{\dot{\mathrm{W}}}{\mathrm{P}} \times 100 \\
\eta_{\text {overall }} & =\frac{27.829}{44} \times 100 \\
\eta_{\text {overall }} & =61.84 \%
\end{aligned}
$$

To do the same amount of Ideal work on air, theoretically, screw compressor required only $30 \mathrm{~kW}$ of the motor. Hence, the efficiency of screw compressor as calculated was more than that of the reciprocating compressor.

$$
\begin{aligned}
& \eta_{\text {overall }}=\frac{\text { Ideal Work }}{\text { Motor Power }} \times 100=\frac{27.892}{30} \times 100 \\
& \eta_{\text {overall }}=92.76 \%
\end{aligned}
$$

Thus,for same operational parameters, the screw compressor results in efficiency increase by $30.92 \%$.

\section{RESULTS \& DISCUSSION}

The table 2 shows saving in motor power and electricity cost in compression process for a full load and no load conditions if screw compression is used. 
Table -2: Electricity cost saving in compressor

\begin{tabular}{|c|c|c|c|}
\hline \multicolumn{2}{|c|}{} & Full Load & No Load \\
\hline \multicolumn{2}{|c|}{ Motor Power (kW) } & 14 & 8 \\
\hline \multirow{2}{*}{$\begin{array}{c}\text { Electricity } \\
\text { Cost } \\
\text { Saving } \\
\text { (Rs.) }\end{array}$} & Daily & $1,509.2$ & 431.2 \\
\cline { 2 - 4 } & Monthly & 45,276 & 12,936 \\
\cline { 2 - 4 } & Annually & $5,43,312$ & $1,55,232$ \\
\hline
\end{tabular}

The table 3 shows saving in pumping cost if thereciprocating compressor is replaced by screw compressor since latter does not require intercooler as it is single stage compression process.

Table -3: Electricity cost saved in Pumping

\begin{tabular}{|c|c|c|}
\hline \multicolumn{2}{|c|}{ Motor Power (kW) } & 1.74 \\
\hline Electricity Cost & For a Day & 321.55 \\
\cline { 2 - 3 } Saving (Rs.) & For a Month & $9,646.56$ \\
\cline { 2 - 3 } & For a Year & $1,15,758.72$ \\
\hline
\end{tabular}

The project carried out at Melog resulted in total monetary savings of Rs.8, 14,302. The category wise savings can be shown in the following table.

Table -4: Total Financial Savings for Screw Compressor

\begin{tabular}{|c|c|}
\hline Contents & Annual Savings \\
\hline Pumping Cost & $1,15,758$ \\
\hline \multirow{2}{*}{ Compression Cost } & $5,43,312$ (full load) \\
\cline { 2 - 2 } & $1,55,232$ (no load) \\
\hline Total Cost & $8,14,302$ \\
\hline
\end{tabular}

\section{CONCLUSION}

It can be deduced from the study that for low-pressure ratio screw compressor is more efficient than the reciprocating compressor.

The project concluded with the computation and verification of following points:

- Use of screw compressor over reciprocating compressor results in a considerable amount of monetary savings by eliminating pumping cost and minimizing the electric cost.

- Screw compressor gives uninterrupted output whereas reciprocating compressor requires frequent maintenance.

- When the compressed air delivery pressure is $10 \mathrm{~kg} / \mathrm{cm}^{2}$ or below and the volume flow rate required is up to 100 $\mathrm{m}^{3} / \mathrm{hr}$. a single stage screw compressor results in less maintenance and operational cost.

- Though the initial cost of screw compressor is high its operating cost is low as that of the reciprocating compressor.

To sum up, when compared with a standard 2 stage reciprocating compressor, a single stage rotary screw compressor working for delivery pressures of $10 \mathrm{~kg} / \mathrm{cm}^{2}$ or below will result in a more dependable and economical service.

\section{ACKNOWLEDGEMENT}

We thank "Mr. Sandeep Tondapurkar", Plant Head, "Mr. G. K. Walimbe", and Head of Utility Department of MELOG Specialty Chemicals Pvt. Ltd. for allowing us to work on this project and for their support and assistance. They provided us with all the necessary guidance and helped us whenever we needed them. Without their inputs and assistance, this project would not have been possible.

\section{REFERENCES}

[1]. G. Chanukya Reddy, "CFD Studies on Flow through Screw Compressor", M. Tech., Thesis, National Institute of Technology, Rourkela, India, 2007.

[2]. Luo, Xianglong, Jiahao Hu, Jun Zhao, Bingjian Zhang, Ying Chen, and Songping Mo."Multiobjectiveoptimization for the design and synthesis of utility systemswith emission abatement technology concerns", Applied Energy, 2014.

[3]. Instruction book \& parts list,Ingersoll Rand (India). Ltd, Ahmedabad, Gujarat, India, July 2001.

[4]. "Compressed Air System", Bureau of Energy Efficiency, [Online], pp. 49-77. Available: http://www.em-ea.org/guidebooks/book-3/chapter 3.3 compressed air system.

[5]. Chris Schmidt, Kelly Kissock, "Power Characteristics Of Industrial Air Compressors", Thesis, University of Dayton, Department of Mechanical and Aerospace Engineering, Dayton, Ohio, USA, 2002.

[6]. Cengal, Y. and Boles, M., "Energy Efficient Compressed Air Systems", Thermodynamics, WGBMcGraw-Hill, 1998.

[7]. Spare parts manual, Kirloskar Pneumatic Co. Ltd, Pune, Maharashtra, India, 2003.

\section{BIOGRAPHIES}

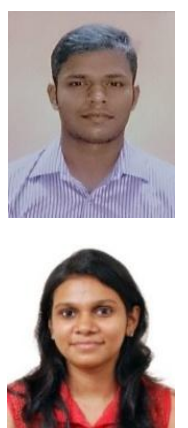

Deeptej G. Kolambkar, B.E Student, Department of Mechanical Engineering, Datta Meghe College of Engineering.

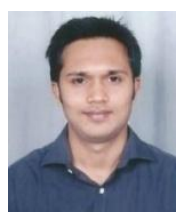

Pooja K. Nandu, B.E Student, Department of Mechanical Engineering, Datta Meghe College of Engineering.

Kiran K. Sinkar, B.E Student, Department of Mechanical Engineering, Datta Meghe College of Engineering.

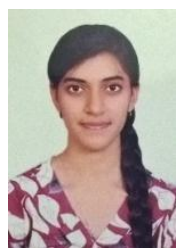

Simran A. Sohal, B.E Student, Department of Mechanical Engineering, Datta Meghe College of Engineering. 